\title{
Aplicação de Dessecantes na Cultura de Soj A: Antecipação da Colheita e Produção de Sementes ${ }^{1}$
}

\author{
Application of Desiccants on Soybean Crop Glycine max: Harvest Anticipation and Seed Yield
}

LACERDA, A.L.S. ${ }^{2}$, LAZARINI, E. ${ }^{3}$, SÁ, M.E. ${ }^{3}$ e WALTER FILHO, V.V. ${ }^{5}$

\begin{abstract}
RESUMO - Este trabalho foi conduzido no município de Selvíria-MS, semeando soja do cultivar IAC-15. O delineamento experimental utilizado foi o de blocos casualizados, estando os

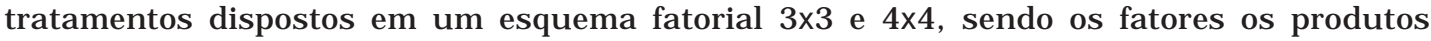
(dessecantes) e as épocas de aplicação, nos anos agrícolas 1996/97 e 1997/98, respectivamente. Os dessecantes utilizados foram: paraquat, diquat e mistura paraquat + diquat, nas dosagens de 0,4; 0,3 e 0,2+0, 15 em 1996/97, respectivamente, e os mesmos tratamentos em 1997/98, além do glufosinato de amônio na dosagem de 0,4 kg i.a. ha-1 em 1997/98. Como épocas, foram realizadas três aplicações em 1996/97 e quatro em 1997/98, todas espaçadas de cinco dias a partir do estádio fenológico médio da cultura $\mathrm{R}_{6}$. Concluiu-se que os dessecantes utilizados mostraram-se eficientes na dessecação da soja; foi possivel obter antecipação da colheita de sementes de soja, sem alterar a produção, por um período máximo de sete dias.
\end{abstract}

Palavras-chave: Paraquat, diquat, glufosinato de amônio, dessecação.

ABSTRACT - This research was carried out in Selviria-MS, Brazil, during the growing seasons of 1996/97 and 1997/98, using the soybean cultivar IAC-15. The experimental design was arranged in randomized complete blocks in a $3 \times 3$ and $4 \times 4$ factorial scheme during 1996/97 and 1997/98, respectively, with the factors being the products (desiccants) and timing of application. The desiccants sprayed were: paraquat, diquat and a mixture of paraquat + diquat at rates of 0.4; 0.3 and $0.2+0.15$ in 1996/97 and the same treatments in 1997/98 added to ammonium glufosinate at $0.4 \mathrm{~kg}$ a.i. $\mathrm{ha}^{-1}$ in 1997/98. The timing of application was spaced every five days, starting from the soybean vegetative stage R6. The tested desiccants were efficient on the soybean desiccation; it was possible to obtain grain harvest anticipation, without yield reduction, in a maximum period of seven days.

Key words: Paraquat, diquat, ammonium glufosinate, desiccation.

\section{INTRODUÇÃO}

A maturação da semente compreende uma série de alterações morfológicas, fisiológicas e funcionais, que ocorrem a partir da fertilização do óvulo, prosseguindo até o momento em que as sementes estão em condições para a colheita (Delouche, 1971). Durante esse processo, verificam-se alterações no peso da matéria seca, no teor de umidade, no tamanho, na

Recebido para publicação em 24/4/2001 e na forma revisada em 17/12/2001.

2 Eng ${ }^{\circ}$-Agrônomo, Doutorando em Agronomia do Dep. de Produção Vegetal - ESALQ/USP - Av. Pádua Dias, 11, Caixa Postal 9, 13417-950 -Piracicaba-SP. ${ }^{3}$ Professores do Dep. de Fitotecnia, Economia e Sociologia Rural - FEIS/UNESP - Av. Brasil, 56, 15385-000 Ilha Solteira-SP. ${ }^{4}$ Prof. do Dep. de Matemática - FEIS/UNESP.

Planta Daninha, Viçosa-MG, v.19, n.3, p.381-390, 2001 
germinação e no vigor das sementes (Delouche, 1971; Potts, 1971), ocorrendo também alterações na composição química das sementes, ou seja, alterações nos teores de carboidratos, proteínas, lipídios, entre outras (Delouche, 1971). O conhecimento da maturidade fisiológica é importante, pois caracteriza o momento em que a semente se desliga fisiologicamente da planta e passa a sofrer maior influência das condições ambientais (Marcos Filho, 1986).

A colheita de sementes de soja no estádio de maturação fisiológica $\left(R_{7}\right)$ seria, teoricamente, o mais indicado, pois é o momento em que se obtém a melhor qualidade fisiológica, ou seja, elas apresentam máxima germinação e vigor e seu grau de deterioração é mínimo (Pollock \& Roos, 1972; França Neto, 1984). Nesse estádio, o teor de água da semente é bastante elevado (acima de 45\%).

De acordo com EMBRAPA (1998), a colheita constitui uma importante etapa no processo produtivo da soja, principalmente pelos riscos a que está sujeita a lavoura destinada ao consumo ou à produção de sementes. A colheita deve ser iniciada tão logo a soja atinja o estádio $\mathrm{R}_{8}$ (ponto de colheita), a fim de evitar perdas na qualidade do produto. Nessa ocasião, devese atentar para que a colheita seja realizada com teor de umidade entre 13 e 15\%, condições estas em que são minimizados os problemas de danos mecânicos e perdas na colheita.

A antecipação da colheita da soja só é possivel usando-se dessecantes. O grau de dessecação está estritamente relacionado com a injúria causada pelo produto à membrana da célula, permitindo rápida perda de água.

Ensaios conduzidos por Fonseca (1984) com a variedade UFV-2 evidenciaram que a produção de sementes aumentou à medida que as aplicações de paraquat foram realizadas mais próximas da maturação de colheita $\left(\mathrm{R}_{8}\right)$, atingindo o máximo em torno do estádio $R_{7,5}$. Mendonça (1984), trabalhando com o cultivar IAC-8, observou que as plantas de soja que sofreram dessecação com paraquat $\left(1,0 \mathrm{~L} \mathrm{ha}^{-1}\right)$ aos 59 dias após o início do florescimento, com teor de água dos grãos acima de $60 \%$, permitiram a colheita mecânica somente 19 dias após a aplicação do produto. Freitas (1984a), utilizando o mesmo cultivar e aplicando o dessecante paraquat $\left(2,0 \mathrm{~L} \mathrm{ha}^{-1}\right)$ em épocas estabelecidas segundo os estádios $\mathrm{R}_{6}, \mathrm{R}_{7}$ e $\mathrm{R}_{8}$, verificou que a aplicação do produto no estádio $\mathrm{R}_{7}$ permitiu antecipação de 18 dias na colheita e não afetou a capacidade de produção de sementes. Quando a aplicação foi feita antes da maturidade fisiológica (estádio $\mathrm{R}_{6}$ ), a produção foi menor, porém a diferença não foi significativa.

Freitas (1984b), avaliando o efeito da aplicação de três dessecantes químicos $(2,4 \mathrm{D}$, paraquat e glyphosate) no cultivar IAC-8 aos 73 dias após o florescimento da soja, quando as sementes se encontravam com teor médio de água de 40,8\%, verificou que a produção e o peso de 100 sementes não foram afetados pelas aplicações dos diferentes dessecantes nas doses em que foram testados, provavelmente por terem sido aplicados todos em uma mesma data, quando as sementes já haviam atingido a maturidade fisiológica.

A prática da dessecação na cultura da soja carece de trabalhos mais recentes, em razão de novas tecnologias terem sido incorporadas nesta cultura, principalmente em relação a variedades. Um fator adicional que vem tornando a agricultura, ainda, viável em algumas regiões é a prática da safrinha após a cultura da soja. Nesse sentido, objetivou-se no presente trabalho determinar a melhor época de aplicação de dessecantes na cultura da soja, de forma a permitir máxima antecipação da colheita, sem afetar a produção de sementes, em Selvíria-MS.

\section{MATERIAL E MÉTODOS}

Os ensaios foram conduzidos na área experimental da Fazenda de Ensino e Pesquisa (FEP), pertencente à Faculdade de Engenharia de Ilha Solteira - UNESP, localizada no município de Selvíria - MS, apresentando como coordenadas geográficas $51^{\circ} 22^{\prime} \mathrm{W}$ e $20^{\circ} 22$ 'S e aproximadamente $335 \mathrm{~m}$ de altitude, $1.370 \mathrm{~mm}$ de precipitação e $23,5^{\circ} \mathrm{C}$ de temperatura média anual. Os dados meteorológicos, observados durante o período de condução dos experimentos (aplicação dos tratamentos e avaliações), foram registrados diariamente no posto meteorológico da FEP, localizado próximo da área experimental, e estão apresentados nas Tabelas 1 e 2 . As semeaduras e a germinação 
ocorreram em 20/11/96 e 27/11/96, 04/12/ 97 e 10/12/97, nos anos agrícolas 1996/97 e 1997/98, respectivamente. O manejo da cultura foi realizado de acordo com as recomendações da EMBRAPA (1996).

Tabela 1 - Precipitação e temperaturas máxima e mínima registradas no posto meteorológico da Fazenda de Ensino e Pesquisa da UNESP, no período de fevereiro e março/ 97. Selvíria-MS

\begin{tabular}{|c|c|c|c|c|c|c|}
\hline \multirow{2}{*}{ Dia } & \multicolumn{2}{|c|}{$\begin{array}{c}\text { Precipitação } \\
(\mathrm{mm})\end{array}$} & $\begin{array}{c}\text { Temperatura Máx. } \\
\left({ }^{\circ} \mathrm{C}\right)\end{array}$ & $\begin{array}{c}\text { Temperatura Mín. } \\
\left({ }^{\circ} \mathrm{C}\right)\end{array}$ \\
\cline { 2 - 7 } & Fevereiro & Março & Fevereiro & Março & Fevereiro & Março \\
\hline 1 & 21,4 & 0 & 31,0 & 32,5 & 19,7 & 21,1 \\
2 & 43,0 & 2,0 & 30,2 & 32,2 & 19,9 & 20,8 \\
3 & 15,2 & 0 & 16,8 & 31,1 & 21,8 & 22,7 \\
4 & 2,0 & 0 & 27,0 & 30,0 & 21,2 & 22,7 \\
5 & 2,2 & 0 & 30,1 & 31,3 & 24,0 & 23,7 \\
6 & 0 & 0 & 32,0 & 32,5 & 21,4 & 20,6 \\
7 & 0 & 30,4 & 32,3 & 32,6 & 25,0 & 23,6 \\
8 & 0 & 0 & 33,0 & 32,2 & 21,5 & 20,2 \\
9 & 0 & 2,9 & 34,0 & 32,5 & 21,8 & 20,5 \\
10 & 0 & 0 & 33,7 & 32,3 & 21,2 & 23,6 \\
11 & 1,0 & 0 & 34,0 & 32,1 & 19,2 & 23,0 \\
12 & 0 & 0 & 31,6 & 32,6 & 21,9 & 23,4 \\
13 & 11,6 & 2,5 & 32,1 & 33,8 & 24,8 & 24,3 \\
14 & 4,0 & 24,2 & 31,7 & 31,1 & 23,1 & 22,9 \\
15 & 4,0 & 13,8 & 28,7 & 29,2 & 19,5 & 19,0 \\
16 & 0 & 51,6 & 29,2 & 29,0 & 19,4 & 19,0 \\
17 & 5,2 & 0 & 30,5 & 28,8 & 24,5 & 22,0 \\
18 & 0 & 0 & 30,1 & 29,8 & 23,1 & 22,3 \\
19 & 15,2 & 0 & 32,0 & 30,7 & 24,4 & 23,3 \\
20 & 0 & 0 & 30,8 & 30,8 & 22,9 & 23,0 \\
21 & 11,8 & 0 & 31,0 & 31,2 & 24,3 & 23,1 \\
22 & 0 & 0 & 32,5 & 31,7 & 20,6 & 20,0 \\
23 & 0 & 0 & 34,5 & 32,0 & 21,0 & 24,0 \\
24 & 0 & 0 & 34,3 & 33,0 & 25,6 & 22,5 \\
25 & 0 & 0 & 33,6 & 31,5 & 26,6 & 23,9 \\
26 & 0 & 0 & 34,0 & 30,0 & 25,8 & 22,6 \\
27 & 3,0 & 0 & 33,8 & 30,5 & 26,8 & 18,6 \\
28 & 0 & 0 & 33,0 & 30,7 & 24,8 & 19,0 \\
29 & --- & 0 & --- & 31,5 & --- & 16,6 \\
30 & --- & 38,3 & --- & 27,5 & --- & 17,6 \\
31 & --- & 31,4 & --- & 22,1 & --- & 18,0 \\
\hline Total & 139,6 & 197,1 & --- & --- & --- & --- \\
\hline Média & --- & --- & 30,6 & 30,9 & 22,7 & 21,5 \\
\hline
\end{tabular}

O delineamento experimental utilizado foi em blocos casualizados, com quatro repetições. Os tratamentos utilizados foram dispostos em um esquema fatorial $3 \times 3$ e $4 \times 4$, sendo os fatores constituídos pelos dessecantes e pelas épocas de aplicação dos dessecantes, nos anos agrícolas 1996/97 e 1997/98, respectivamente. As parcelas experimentais constaram de 10 linhas de $12 \mathrm{~m}$ de comprimento, espaçadas de $0,5 \mathrm{~m}$, considerando-se como área útil as quatro linhas centrais com $5 \mathrm{~m}$ de comprimento, desprezando-se $3,5 \mathrm{~m}$ em cada extremidade da parcela. Foram consideradas como testemunhas as parcelas sem aplicação de dessecantes, colhidas, portanto, no estádio $\mathrm{R}_{8}$. $\mathrm{O}$ cultivar de soja utilizado foi o IAC-15, recomendado para a região, segundo a EMBRAPA (1996).

Tabela 2 - Precipitação e temperaturas máxima e mínima registradas no posto meteorológico da Fazenda de Ensino e Pesquisa da UNESP, no período de março e abril/98. Selvíria-MS

\begin{tabular}{|c|c|c|c|c|c|c|}
\hline \multirow{2}{*}{ Dia } & \multicolumn{2}{|c|}{$\begin{array}{c}\text { Precipitação } \\
(\mathrm{mm})\end{array}$} & \multicolumn{2}{|c|}{$\begin{array}{c}\text { Temperatura Máx. } \\
\left({ }^{\circ} \mathrm{C}\right)\end{array}$} & \multicolumn{2}{|c|}{$\begin{array}{c}\text { Temperatura Mín. } \\
\left({ }^{\circ} \mathrm{C}\right)\end{array}$} \\
\cline { 2 - 7 } & Março & Abril & Março & Abril & Março & Abril \\
\hline 1 & 24,7 & 2,8 & 32,5 & 31,5 & 23,0 & 22,8 \\
2 & 9,6 & 0 & 33,0 & 29,5 & 23,0 & 22,4 \\
3 & 0 & 0 & 28,0 & 28,5 & 21,6 & 19,2 \\
4 & 0 & 3,4 & 32,5 & 28,0 & 23,6 & 15,4 \\
5 & 18,0 & 0 & 33,5 & 28,0 & 22,6 & 19,0 \\
6 & 0 & 0 & 31,0 & 31,5 & 22,8 & 22,2 \\
7 & 1,4 & 10,2 & 33,5 & 28,5 & 18,4 & 21,8 \\
8 & 0 & 61,4 & 34,5 & 30,5 & 22,2 & 20,6 \\
9 & 0 & 0 & 33,5 & 31,5 & 22,8 & 21,4 \\
10 & 0 & 0 & 34,0 & 31,5 & 23,6 & 19,4 \\
11 & 3,4 & 0 & 33,0 & 32,0 & 23,6 & 24,0 \\
12 & 2,3 & 0 & 33,0 & 33,0 & 24,8 & 23,2 \\
13 & 0 & 0 & 32,5 & 34,0 & 23,2 & 23,2 \\
14 & 2,0 & 0 & 33,0 & 33,5 & 23,8 & 24,0 \\
15 & 0 & 5,0 & 32,5 & 34,0 & 23,0 & 23,4 \\
16 & 0 & 12,5 & 32,0 & 30,0 & 23,2 & 23,2 \\
17 & 3,6 & 19,8 & 31,5 & 31,0 & 22,2 & 23,0 \\
18 & 35,4 & 0 & 28,0 & 24,5 & 23,6 & 17,0 \\
19 & 0 & 0 & 32,5 & 25,5 & 23,0 & 15,8 \\
20 & 0 & 0 & 33,0 & --- & 23,6 & --- \\
21 & 2,8 & 0 & 33,5 & 30,0 & 19,4 & 13,7 \\
22 & 0 & 0 & 31,5 & 33,5 & 24,2 & 21,0 \\
23 & 0 & 0 & 32,5 & 33,5 & 23,0 & 22,4 \\
24 & 33,2 & 0 & 34,0 & 34,5 & 23,0 & 22,2 \\
25 & 0 & 0 & 26,0 & 34,5 & 21,6 & 19,2 \\
26 & 0 & 0 & 31,0 & 34,0 & 19,6 & 20,0 \\
27 & 0 & 0 & 32,0 & 34,0 & 22,6 & 22,8 \\
28 & 0 & 20,0 & 34,0 & 33,5 & 25,0 & 24,0 \\
29 & 0 & 3,7 & 34,0 & 22,5 & 24,2 & 21,2 \\
30 & 26,0 & 0 & 25,5 & 22,0 & 22,8 & 14,2 \\
31 & 1,2 & --- & 32,0 & --- & 22,4 & --- \\
\hline Total & 163,6 & 138,8 & --- & --- & --- & --- \\
\hline Média & --- & --- & 34,2 & 30,6 & 22,8 & 20,8 \\
\hline
\end{tabular}


Os dessecantes utilizados no ano agrícola 1996/97 foram: paraquat, diquat e paraquat + diquat (mistura em tanque) nas dosagens de 0,4; 0,2; e 0,2+0,15 g i.a. ha-1 ${ }^{-1}$ respectivamente. Em 1997/98, utilizaram-se os mesmos dessecantes nas mesmas dosagens, acrescentandose mais um tratamento, sendo o glufosinato de amônio o dessecante utilizado, na dosagem de 0,4 g i.a. ha ${ }^{-1}$. Os produtos comerciais utilizados foram Gramoxone, Reglone e Finale. Os intervalos de aplicação foram de cinco em cinco dias, após o início do estádio $\mathrm{R}_{6}$ até o estádio $\mathrm{R}_{7}$. Foram realizadas três aplicações em 1997 e quatro em 1998. Na Tabela 3 encontram-se as datas das aplicações e de colheita dos respectivos tratamentos. Baseou-se em Fehr et al. (1971) para determinação dos estádios reprodutivos $R_{6}, R_{7}$ e $R_{8}$.

Tabela 3 - Datas de aplicações e colheita dos tratamentos

\begin{tabular}{|l|c|c|}
\hline \multicolumn{1}{|c|}{ Aplicação/colheita } & 1997 & 1998 \\
\hline Primeira aplicação & $26 / 02$ & $05 / 03$ \\
Segunda aplicação & $03 / 03$ & $10 / 03$ \\
Terceira aplicação & $08 / 03$ & $15 / 03$ \\
Quarta aplicação & --- & $20 / 03$ \\
Colheita da primeira e segunda aplicações & $10 / 03$ & $27 / 03$ \\
Colheita da terceira aplicação & $15 / 03$ & $27 / 03$ \\
Colheita da quarta aplicação & --- & $03 / 04$ \\
Colheita da testemunha & $10 / 03$ & $03 / 04$ \\
\hline
\end{tabular}

Os dessecantes foram aplicados, sempre no período da manhã, com o auxílio de um pulverizador de barra (Jacto M-12), calibrado para consumo de calda de $300 \mathrm{~L} \mathrm{ha}^{-1}$, conforme recomendação no rótulo dos dessecantes, equipado com bicos do tipo cônico vazio $\left(D_{6}\right)$ no agrícola $1996 / 97$ e bicos do tipo leque $\left(110^{\circ}-\mathrm{SF}-02\right)$ no ano agrícola 1997/98. Utilizou-se espalhante adesivo na proporção de $12 \mathrm{~mL} / 20 \mathrm{~L} \mathrm{de}$ calda, para os dessecantes paraquat, diquat e paraquat + diquat, e de $20 \mathrm{~mL} / 20 \mathrm{~L}$ de calda, para o glufosinato de amônio.

A análise de variância dos dados foi feita pelo teste F. As análises estatísticas foram realizadas com o auxílio do programa SAS. A comparação entre médias dos dados obtidos foi efetuada pelo teste de Tukey a $5 \%$ de probabilidade.

Planta Daninha, Viçosa-MG, v.19, n.3, p.381-390, 2001

\section{Avaliações}

Antecipação da colheita: foi determinada através da diferença de ciclo (emergência à colheita) entre as parcelas que receberam aplicações dos dessecantes e a testemunha.

Características agronômicas: antes da colheita das parcelas, avaliou-se o estande pela contagem das plantas contidas em cada linha da área útil da parcela, em ambos os experimentos. A seguir, arrancaram-se todas as plantas da área útil, as quais, após identificação, foram colocadas em sacos de estopa e levadas para secagem em terreiro. Depois da secagem, elas foram trilhadas mecanicamente, e as sementes obtidas após a limpeza foram pesadas e submetidas à determinação do grau de umidade pelo método da estufa, para correção do peso a 13\% de umidade (base úmida). Após a correção, os dados foram transformados em $\mathrm{kg} / \mathrm{ha}$. Simultaneamente, foi realizada também a avaliação do peso de 100 sementes, de modo semelhante ao da metodologia descrita, pela RAS (Brasil, 1992), para determinação do peso de 1.000 sementes, corrigindo-o também para $13 \%$ de umidade (base úmida). Também foram avaliadas a altura das plantas e a altura da inserção das primeiras vagens, em 10 plantas coletadas ao acaso no tratamento testemunha, nos anos agrícolas 1996/97 e 1997/98. Essa avaliação foi realizada em todos os tratamentos que antecederam todas as aplicações dos dessecantes.

\section{RESULTADOS E DISCUSSÃO}

No ano agrícola 1996/97, as aplicações ocorreram quando a cultura se encontrava com 92, 97 e 102 dias após a emergência, e a colheita foi realizada aos 104 dias para primeira, segunda aplicação e testemunha e aos 109 dias para a terceira aplicação. Nota-se que houve redução no ciclo, pois, segundo IAC (1989), essa variedade caracteriza-se como de ciclo semiprecoce, possuindo ciclo aproximado de 126 dias quando semeada na segunda quinzena de novembro. Essa redução deveu-se, provavelmente, ao déficit hídrico e à temperatura elevada verificados no período de 22/2 a 6/3/97 (Tabela 1), acelerando sua maturação. Deluca D'oro \& Trippi (1987) também verificaram que a presença de déficit hídrico e altas temperaturas acelera a senescência da cultura da soja. 
No ano agrícola 1997/98, a cultura encontrava-se com 91, 96, 101 e 106 dias após a emergência, quando foram realizadas a primeira, segunda, terceira e quarta aplicações, respectivamente. As colheitas ocorreram aos 113 (primeira, segunda e terceira aplicações) e 120 dias (quarta aplicação e testemunha), isto é, 22,17 e 12 dias após a primeira, segunda e terceira aplicações, respectivamente, e 14 dias após a quarta aplicação. Apesar da ocorrência de veranicos na região, durante os meses de março/abril, e de elevadas temperaturas (Tabela 2), não se verificou marcante redução no ciclo da cultura.

Verifica-se, na Tabela 4, que as plantas, em média, apresentavam elevada percentagem de vagens verdes na primeira aplicação, característica pertencente ao estádio $R_{6}$, e que rapidamente as plantas atingiram $R_{8}(08 / 03)$, provavelmente devido às condições climáticas, que favoreceram a senescência das plantas.

Tabela 4 - Estádios de dessecação das vagens nas diferentes épocas de aplicação dos dessecantes

\begin{tabular}{|c|r|r|c|}
\hline \multirow{2}{*}{ Épocas } & \multicolumn{3}{|c|}{ Estádios das Vagens (\%) } \\
\cline { 2 - 4 } & Verdes & Amarelas & Marrons \\
\hline \multicolumn{4}{|c|}{$1996 / 97$} \\
\hline $26 / 02$ & 90 & 9 & 1 \\
$03 / 03$ & 20 & 32 & 48 \\
$08 / 03$ & 0 & 1 & 99 \\
\hline \multicolumn{5}{|c|}{$1997 / 98$} \\
\hline $05 / 03$ & 100 & 0 & 0 \\
$10 / 03$ & 97 & 3 & 0 \\
$15 / 03$ & 75 & 16 & 9 \\
$20 / 03$ & 18 & 22 & 60 \\
\hline
\end{tabular}

No ano agrícola 1997/98, verifica-se, através das porcentagens de vagens verdes, amarelas e marrons (Tabela 4), que as aplicações ocorreram em três distintas fases de desenvolvimento da cultura, ou seja, a primeira e segunda aplicações ocorreram com as plantas em estádio $\mathrm{R}_{6}$; a terceira, praticamente no estádio $\mathrm{R}_{7}$; e a quarta foi realizada com as plantas próximas ao estádio $\mathrm{R}_{8}$, pois, segundo Fehr et al. (1971), é necessário no mínimo 95\% de vagens marrons para se caracterizar esse estádio.
Através das datas de colheita apresentadas na Tabela 3, verifica-se que dessecantes não proporcionaram antecipação da colheita no ano agrícola 1996/97, já que a testemunha foi colhida no mesmo dia em que se realizou a colheita das parcelas referentes à primeira e segunda aplicações. As condições climáticas presentes proporcionaram redução no ciclo da cultura, fazendo com que o benefício da antecipação da colheita usando-se os dessecantes não se concretize. Portanto, quando a cultura da soja se encontra nos estádios de desenvolvimento $R_{6}$ e $R_{7}$, ou seja, em fase final de ciclo, e esta se localiza em uma região em que o clima se caracteriza por apresentar chuvas esparsas e temperaturas elevadas a partir destes estádios de desenvolvimento, não é aconselhável a aplicação de dessecantes, a não ser que algo o justifique, como, por exemplo, presença de plantas daninhas que dificultariam a colheita, retenção foliar, etc.

No ano agrícola 1997/98, os dessecantes aplicados em 5, 10 e 15/3/1998 (primeira, segunda e terceira aplicações, respectivamente) proporcionaram antecipação da colheita de sete dias, o que não ocorreu com a aplicação realizada em 20/3 (quarta aplicação). Durigan \& Carvalho (1980), por meio do uso de dessecantes, obtiveram antecipação de 21 dias, sem afetar as características de produção nem o vigor das sementes de soja. Durigan (1979), Andreoli \& Ebeltoft (1979) e Fraga (1988), usando dessecantes, também conseguiram antecipar a colheita de soja e reduzir a deterioração das sementes no campo. Bastidas Filho \& Barros (1980), utilizando três variedades e duas épocas de aplicação, observaram que o paraquat proporcionou redução acentuada no teor de umidade das sementes das três variedades, permitindo antecipação de 8 a 14 dias na colheita. Segundo os autores, fatores como variedades e características climáticas dos locais de realização dos ensaios podem interferir nos resultados obtidos.

Os valores observados para a avaliação de estande (Tabela 5), apesar da ocorrência de diferença entre épocas, encontram-se próximos da população de 400.000 plantas/ha, desejada para a variedade nessa época de semeadura, segundo EMBRAPA (1996). Também se observou que não houve diferença significativa, em função dos dessecantes e da comparação do fatorial com a testemunha, mostrando que o 
estande provavelmente não influenciou o efeito dos dessecantes. A altura de plantas e inserção das primeiras vagens encontravam-se na época de colheita com valores médios em torno de 102 e 9,2 cm, respectivamente, caracterizando a cultura como apta para colheita mecânica.

Tabela 5 - Análise de variância e médias de estande, produção de sementes e peso de 100 sementes, obtidas em função dos dessecantes utilizados e das épocas de aplicação. Ano agrícola 1996/97 ${ }^{\prime}$

\begin{tabular}{|l|c|c|c|}
\hline Épocas/Dessecantes & $\begin{array}{c}\text { Estande } \\
\left(\text { planta }^{-1}\right)\end{array}$ & $\begin{array}{c}\text { Produção } \\
\left(\mathrm{kg} \mathrm{ha}^{-1}\right)\end{array}$ & $\begin{array}{c}\text { Peso de 100 } \\
\text { sementes } \\
(\mathrm{g})\end{array}$ \\
\hline Testemunha & 21,8 & 2.347 & $12,5 \mathrm{~b}$ \\
Fatorial & 20,5 & 2.296 & $12,9 \mathrm{a}$ \\
\hline $26 / 02$ & $21,0 \mathrm{ab}$ & $2.179 \mathrm{~b}$ & $12,5 \mathrm{~b}$ \\
$03 / 03$ & $22,3 \mathrm{a}$ & $2.420 \mathrm{a}$ & $13,4 \mathrm{a}$ \\
$08 / 03$ & $18,1 \mathrm{~b}$ & $2.272 \mathrm{ab}$ & $13,0 \mathrm{a}$ \\
\hline Paraquat & 20,9 & 2.339 & 13,1 \\
Diquat & 20,8 & 2.268 & 12,8 \\
Paraquat+diquat & 19,6 & 2.265 & 13,0 \\
\hline Teste F & & & \\
Testem. vs. Fatorial & $0,48^{\mathrm{ns}}$ & $0,23^{\mathrm{ns}}$ & $5,19^{*}$ \\
Épocas (E) & $4,32^{*}$ & $3,58^{*}$ & $13,30^{* *}$ \\
Dessecantes (D) & $0,53^{\mathrm{ns}}$ & $0,43^{\mathrm{ns}}$ & $1,72^{\mathrm{ns}}$ \\
E * D & $1,19^{\mathrm{ns}}$ & $0,87^{\mathrm{ns}}$ & $0,75^{\mathrm{ns}}$ \\
DMS Tukey (5\%) & \multicolumn{3}{|c}{} \\
Épocas e Dessecantes & 3,6 & 225,0 & 0,4 \\
CV (\%) & 17,3 & 9,7 & 3,2 \\
\hline II Médias seguidas da mesma letra na coluna não diferem \\
estatisticamente entre si pelo teste de Tukey a 5\% de probabilidade. \\
vs. = versus.
\end{tabular}

Quanto à produção, verifica-se que a primeira aplicação $(26 / 2)$ foi a que proporcionou menor valor, diferindo da segunda aplicação (3/3/97). Provavelmente, nessa primeira época, as sementes ainda não se encontravam totalmente formadas (com seu máximo acúmulo de matéria seca), pois as plantas se encontravam no estádio $\mathrm{R}_{6}$ no momento da aplicação. Fraga (1988) observou que nos estádios $R_{6}$ e $\mathrm{R}_{6,5}$ ocorreu redistribuição de fotoassimilados das plantas em que se aplicaram dessecantes para as sementes, permitindo aumento do peso e, possivelmente, possibilitando que as sementes continuassem o processo de maturação.

São feitas recomendações de aplicações de dessecantes quando as plantas têm $80 \%$ de vagens amareladas e $20 \%$ de secas, com folhas amareladas (Bastidas et al., 1971), ou quando as vagens estão amarelando e 50\% das folhas já estão amarelas (Thomas et al., 1974), ou, ainda, quando os ramos e as vagens estão marrons e as folhas caídas (Hammerton, 1972). No momento da segunda aplicação a lavoura apresentava, em média, 32\% de vagens amarelas e $48 \%$ de vagens marrons, o que provavelmente já se encontrava além do ponto recomendável para a aplicação dos dessecantes. Como a produção obtida nas parcelas pertencentes à primeira aplicação foi menor que na segunda, o ponto ideal para a aplicação encontra-se entre essas duas épocas.

Não se observou diferença quanto à produção entre testemunha e dessecantes e entre dessecantes. Esses resultados também foram observados por Andreoli \& Ebeltoft (1979), Durigan (1979) e Fraga (1980). Entretanto, efeitos negativos na produção, devido à aplicação de dessecantes, foram observados por Caviness \& Berger (1966), Bovey et al. (1975) e Gigax \& Burnside (1976).

O menor peso de 100 sementes obtido na primeira aplicação vem justificar a menor produção obtida, confirmando que, nesse momento, as sementes ainda não se encontravam com seu máximo acúmulo de matéria seca e que não houve continuidade no processo de translocação de fotoassimilados para as sementes após a aplicação dos dessecantes, contrariando os resultados observados por Fraga (1988). Apenas foi verificada, quando se comparou testemunha $\mathrm{x}$ fatorial, diferença significativa, apresentando o fatorial média superior à testemunha. Isso deve-se aos valores mais elevados obtidos em média para a segunda e terceira aplicações, em relação à testemunha; no entanto, isso não resultou em diferença significativa na produção.

Na Tabela 6 encontram-se as médias de estande, altura das plantas e inserção das primeiras vagens, produção e peso de 100 sementes, referentes ao ano agrícola 1997/98. Os valores de estande observados estão abaixo dos obtidos em 1996/97. Mesmo assim, foram obtidas maiores produtividades nesse ano agrícola. Isso demonstra que a cultura da soja suporta uma oscilação grande de estande e que sua produção está mais correlacionada com as condições climáticas e os demais fatores (adubação, pragas, etc.) do que com relação ao estande, dentro de determinados limites. 
Tabela 6 - Análise de variância e médias de estande, altura de planta e de inserção das primeiras vagens, produção e peso de 100 sementes, obtidas em função dos dessecantes utilizados e das épocas de aplicação. Ano agrícola 1997/98 ${ }^{1 /}$

\begin{tabular}{|c|c|c|c|c|c|}
\hline Épocas/Dessecantes & $\begin{array}{c}\text { Estande } \\
\left(\text { planta } \mathrm{m}^{-1}\right)\end{array}$ & $\begin{array}{l}\text { Altura das } \\
\text { plantas } \\
(\mathrm{cm})\end{array}$ & $\begin{array}{c}\text { Inserção de } \\
\text { vagens } \\
(\mathrm{cm})\end{array}$ & $\begin{array}{c}\text { Produção } \\
\left(\mathrm{kg} \mathrm{ha}^{-1}\right)\end{array}$ & $\begin{array}{c}\text { Peso de } 100 \\
\text { sementes } \\
(\mathrm{g})\end{array}$ \\
\hline Fatorial & 14,7 & 95 & 9,8 & 3.454 & 15,6 \\
\hline Testemunha & 14,3 & 93 & 11,7 & 3.205 & 14,9 \\
\hline $05 / 03$ & $15,1 \mathrm{ab}$ & 95 & 9,5 & $3.185 \mathrm{~b}$ & $14,1 \mathrm{~b}$ \\
\hline $10 / 03$ & $13,8 \mathrm{~b}$ & 96 & 10,0 & $3.377 \mathrm{~b}$ & $15,8 \mathrm{a}$ \\
\hline $15 / 03$ & $15,2 \mathrm{a}$ & 96 & 9,9 & $3.823 \mathrm{a}$ & $16,6 \mathrm{a}$ \\
\hline $20 / 03$ & $15,0 \mathrm{ab}$ & 93 & 10,0 & $3.433 \mathrm{ab}$ & $15,9 \mathrm{a}$ \\
\hline Paraquat & 14,7 & 96 & 10,1 & $3.214 \mathrm{~b}$ & 15,3 \\
\hline Diquat & 14,6 & 97 & 9,7 & $3.651 \mathrm{a}$ & 16,0 \\
\hline Paraquat+diquat & 15,2 & 94 & 9,4 & $3.341 \mathrm{ab}$ & 15,5 \\
\hline Gluf. de amônio & 14,6 & 94 & 10,0 & $3.611 \mathrm{ab}$ & 15,7 \\
\hline \multicolumn{6}{|l|}{ Teste F } \\
\hline Testemunha vs. Fatorial & $0,55^{\mathrm{ns}}$ & $0,39^{\mathrm{ns}}$ & $67,00^{\mathrm{ns}}$ & $0,01^{\mathrm{ns}}$ & $0,38^{\mathrm{ns}}$ \\
\hline Épocas (E) & $4,95^{*}$ & $1,09^{\mathrm{ns}}$ & $0,35^{\mathrm{ns}}$ & $6,12 *$ & $17,07 * *$ \\
\hline Dessecantes (D) & $0,42^{\mathrm{ns}}$ & $0,70^{\mathrm{ns}}$ & $0,16^{\mathrm{ns}}$ & $3,80 *$ & $1,37^{\mathrm{ns}}$ \\
\hline $\mathrm{E} * \mathrm{D}$ & $0,71^{\mathrm{ns}}$ & $1,51^{\mathrm{ns}}$ & $1,32^{\mathrm{ns}}$ & $0,97^{\mathrm{ns}}$ & $1,94^{\mathrm{ns}}$ \\
\hline \multicolumn{6}{|l|}{ DMS Tukey (5\%) } \\
\hline Épocas e Dessecantes & 2,4 & 7,2 & 1,7 & 407,0 & 0,9 \\
\hline $\mathrm{CV}(\%)$ & 5,6 & 8,1 & 18,1 & 12,6 & 6,5 \\
\hline
\end{tabular}

1/ Médias seguidas da mesma letra na coluna não diferem estatisticamente entre si pelo teste de Tukey a 5\% de probabilidade. vs. $=$ versus .

Quanto à altura de plantas e inserção das primeiras vagens, verifica-se que não houve diferença significativa entre os valores obtidos para épocas e dessecantes utilizados e entre o fatorial e a testemunha, evidenciando que as plantas já se encontravam plenamente desenvolvidas a partir da primeira aplicação. Por ser uma variedade de crescimento determinado, pouco desenvolvimento da planta ocorre após o florescimento, e, quando isso acontece, está mais relacionado ao desenvolvimento das partes existentes do que à emissão de novos nós e folhas. Em média, as plantas atingiram $95 \mathrm{~cm}$ de altura (fatorial), sendo altamente favorável à colheita mecânica. Segundo Bonetti (1983), $65 \mathrm{~cm}$ é a altura mínima desejável para a realização dessa operação. Considerando a inserção das primeiras vagens a uma média de 9,8 cm de altura e a citação do mesmo autor, como sendo de $10 \mathrm{~cm}$ a altura de inserção das primeiras vagens desejável para a colheita mecânica, verifica-se não ser este parâmetro o fator negativo no aumento do percentual de perdas durante a colheita, porém Queiroz et al. (1981) sugerem que esse valor deve ser superior a $13 \mathrm{~cm}$.

Avaliando os dados de produção, verificase que não houve diferença significativa entre testemunha e fatorial, apesar de este ter proporcionado maior valor absoluto. Entre épocas de aplicação dos dessecantes, observou-se que a primeira aplicação foi a que proporcionou menor valor de produção, provavelmente pela cultura se encontrar ainda no estádio $\mathrm{R}_{6}$, sendo característica deste estádio o desenvolvimento da semente com grande acúmulo de matéria seca. Nas demais aplicações foi obtido o maior valor de produção. Considerando que a colheita da quarta aplicação ocorreu no mesmo período da testemunha, conclui-se que as condições em que ocorreu a terceira aplicação são as mais recomendadas para a aplicação dos dessecantes na cultura da soja.

Características como porcentagem de vagens amarelas e marrons (Tabela 4), grau de 
umidade das sementes, condições ambientais e estado de senescência da planta, analisadas em conjunto, podem auxiliar na determinação da melhor época de aplicação de dessecantes na cultura da soja, visando maior antecipação da colheita, sem alterar a produção e obter sementes de melhor qualidade fisiológica e sanitária. Nos dois anos agrícolas avaliados, detectou-se que o melhor momento para aplicação dos dessecantes poderá resumir-se em um intervalo de dois a três dias apenas. Assim, a prática da aplicação de dessecantes deve ser acompanhada de conhecimento preciso da cultura (variedade, ciclo, hábito de crescimento, condições climáticas da região, etc.).

Fonseca (1984) evidenciou que a produção das sementes aumentou à medida que as aplicações de paraquat foram realizadas mais próximas da colheita (estádio $\mathrm{R}_{8}$ ), atingindo o máximo em torno do estádio $R_{7.5}$. Segundo Fraga (1980), a maturação fisiológica das sementes de soja, variedade UFV-5, ocorreu no estádio $\mathrm{R}_{7}$, não se verificando, posteriormente, ganho significativo de peso pelas sementes. Fraga (1988) afirma que a dessecação de plantas de soja com paraquat parece ser possivel a partir do estádio $\mathrm{R}_{6,5}$.

Com base na produção obtida pela testemunha e comparando com a obtida na terceira aplicação, verifica-se que a aplicação de dessecantes nesse estádio de desenvolvimento tornase viável em termos de encurtamento do ciclo da cultura, tendo-se menor possibilidade de perdas, pois, como observado, foi obtida menor produtividade com a parcela testemunha, em que não houve aplicação de dessecantes.

Também se observaram diferenças significativas entre os efeitos de dessecantes na produtividade em 1997/98, talvez pelo fato de o paraquat proporcionar secagem mais rápida de folhas e ramos, podendo ter interrompido a translocação de reservas para as sementes mais rapidamente que os demais dessecantes. Freitas (1984a) e Fraga (1988) comprovaram a efetividade do paraquat na dessecação de plantas, em relação a outros dessecantes. O efeito de épocas também foi significativo para peso de 100 sementes, evidenciando que a menor produção obtida ocorreu na mesma época em que se obteve menor peso de 100 sementes.

\section{CONCLUSÕES}

Nas condições em que foram realizados os experimentos e por meio dos dados obtidos, pode-se concluir que:

- É possível obter antecipação de colheita de sementes de soja sem alterar a produção por um período de no máximo sete dias, dependendo das condições edafoclimáticas.

- O período ideal para aplicação dos dessecantes na cultura da soja é muito curto e sua determinação deve ser em função principalmente do estádio de desenvolvimento das plantas.

- Em final de ciclo (presença de senescência de folhas e alta porcentagem de vagens amarelas) da cultura de soja, quando ocorrem condições favoráveis à sua maturação (alta temperatura e baixa umidade), não se recomenda dessecar soja com fins de antecipação da colheita.

- Os produtos utilizados mostraram-se eficientes na dessecação de soja.

\section{AGRADECIMENTOS}

A FAPESP, pelo apoio financeiro para realização deste trabalho.

\section{LITERATURA CITADA}

ANDREOLI, C.; EBELTOFT, D.C. Dessecantes no rendimento e na qualidade da semente de soja. Pesq. Agrop. Bras., v.14, p.135-139, 1979.

BASTIDAS FILHO, G.C.; BARROS, A.C.S.A. Efeitos de dessecantes na maturação e na qualidade de sementes de soja (Glycine max (L.) Merrill). Tecnol. Semente, v.3, p.19-26, 1980.

BASTIDAS, G.; FRANCO, H.; CRUZ, R. Desfoliantes en soya (Glycine $\max (\mathrm{L}$.$) Merrill). Acta Agron.,$ v.21, p.51-58, 1971.

BOLDT, A.F. Relação entre os caracteres de qualidade de vagem e da semente de soja (Glycine $\max ($ L.) MerrilI). Viçosa: UFV, 1982. 70p. Tese (Doutorado em Fitotecnia) Universidade Federal de Viçosa, 1982.

BONETTI, L.P. Cultivares e seu melhoramento genético. In: VERNETTI, F.J., coord. Soja: genética e melhoramento. Campinas: Fundação Cargill, 1983. p.741-794. 
BOVEY, R.W.; MILLER, F.B.; BOUR, J.R. Preharvest desication of grain sorghum with glyphosate. Agron. J ., v.67, p.618-621, 1975.

BRASIL, Ministério da Agricultura. Regras para análise de sementes. Brasília: SNDA / CLAV, 1992. 365p.

CAVINESS, C.E.; BERGER, A. Chemical defoliants and desicants on soybean plants. Ark. Farm. Res., v.15, p.35-46, 1966.

DELUCA D'ORO, G.M.; TRIPPI, V.S. Effect of stress conditions induced by temperature, water and rain on senescence development. Plant Cell Physiol., v.28, p.1389-96, 1987.

DELOUCHE, J.C. Seed maturation. In: HANDBOOK of seed technology. Mississipi: Mississipi State University, 1971. p.17-21.

DURIGAN, J. Efeitos de aplicação em pré colheita de dessecante em duas cultivares de soja (Glycine $\max ($ L.) Merrill). Jaboticabal: UNESP, 1979. 90p. Dissertação (Mestrado em Fitotecnia) - Faculdade de Ciências Agrárias e Veterinária de Jaboticabal, Universidade Estadual Paulista, 1979.

DURIGAN, J.C.; CARVALHO, N.M. Aplicação em précolheita de dessecantes em duas cultivares de soja (Glycine max (L.) Merrill). II. Efeitos sobre a incidência de fungos nas sementes. Planta Daninha, v.2, p.116-121, 1980.

EMPRESA BRASILEIRA DE PESQUISA AGROPECUÁRIA - EMBRAPA. Recomendações técnicas para cultura da soja na região central do Brasil, 1996/ 1997. Londrina: 1996. 164p. (Documentos, 96)

EMPRESA BRASILEIRA DE PESQUISA AGROPECUÁRIA - EMBRAPA. Recomendações técnicas para cultura da soja na região central do Brasil, 1998/ 1999. Londrina: EMBRAPA, 1998. 182p. (Documentos, 120)

FEHR, W.E.; CAVINES, C.E.; BURMOOD,D.T.; PENNINGTON, J.S. Stage of development descriptons for soybeans, Glycine max (L.) Merrill. Crop Sci., v.11, p.929-931, 1971.

FONSECA, N. Influência da aplicação de paraquat sobre a produção e a qualidade da semente de soja (Glycine max (L.) Merrill). Viçosa: Universidade Federal de Viçosa, 1984. 48p. Dissertação (Mestrado em Fitotecnia) - Universidade Federal de Viçosa, 1984.
FRAGA, A.C. Determinação da maturação fisiológica das sementes de soja e de outras características agronômicas, em três épocas de semeadura. Viçosa: UFV, 1980. 47p. Dissertação (Mestrado em Fitotecnia) Universidade Federal de Viçosa, 1984.

FRAGA, A.C. Estudo sobre a utilização de dessecantes na produção de sementes de soja (Glycine $\max ($ L.) Merrill). Viçosa: UFV, 1988. 91 p. Tese (Doutorado em Fitotecnia) Universidade Federal de Viçosa, 1988.

FRANÇA NETO, J.B. Qualidade fisiológica da semente. In: - Qualidade fisiológica e sanitária de sementes de soja. Londrina: EMBRAPA-CNPSo, 1984. p.1-24 (EMBRAPACNPSo. Circular Técnica, 1).

FREITAS, C.E. Aplicação em pré-colheita de três dessecantes em plantas de soja (Glycine max (L.) Merrill, do cultivar IAC-8. Jaboticabal: UNESP, 1984. 74p. Graduação (Monografia) Universidade Estadual Paulista, 1984a.

FREITAS, E.L. Efeitos do dessecamento realizados em diferentes estádios reprodutivos anteriores à colheita da soja (Glycine max (L.) MerrilI), c.v. IAC-8. Jaboticabal: UNESP, 1984b. 68p. Graduação (Monografia) - Faculdade de Ciências Agrárias e Veterinária de Jaboticabal, Universidade Estadual Paulista, 1984b.

GIGAX, D.R.; BURNSIDE, O.C. Chemical desication of grain sorghum. Agron. J ., v.68, p.645-649, 1976.

HAMMERTON, J.L. Effects of weed competition, defoliation and time of harvest on soybeans. Expl. Agric., v.8, p.333-338, 1972.

INSTITUTO AGRONÔMICO DE CAMPINAS. Soja: IAC - 15. Campinas: IAC, 1989. (folder).

MARCOS FILHO, J. Produção de sementes de soja. Campinas: Fundação Cargill, 1986. 86p.

MENDONÇA, A.A. Efeitos da aplicação, em précolheita, de dessecantes em plantas de soja (Glycine max (L.) Merrill) do cultivar IAC-8. Jaboticabal: UNESP, 1984. 84p. Graduação (Monografia) Faculdade de Ciências Agrárias e Veterinária de Jaboticabal, Universidade Estadual Paulista, 1984. 
PEETZ, V.S. Mercado de produtos agrícolas: Soja. Inf. Econom., v.29, p.85-90, 1999.

POTTS, H.C. Seeds: development, struture, function. Mississipi: Mississipi State University, 1971. p.37-51.

POLLOCK, B.M.; ROOS, E.E. Fisiologia da semente. Brasília: AGIPLAN, 1972. 289p.
QUEIROZ, F.F.; NEUMAIER, N.; TORRES, E.; PEREIRA, L.A.G.; BIANCHETTI, A.; TEREZAWA, F.; PALHANO, J.B.; YAMASHITA, J. Recomendações técnicas para a colheita mecânica. In: MYASAKA, S.; MEDINA, J.C., eds. A soja no Brasil. Campinas: ITAL, 1981. p.701-10.

THOMAS, G.D.; IGNOFFO, C.M.; BIEVER, K.D.; SMITH, D.B. Influence of defoliation and depodding on yield of soybeans. J. Econ. Entomol., v.67, p.683-685, 1974. 